\title{
Plasticity and the genetics of reproductive behaviour in the monocarpic perennial, Lobelia inflata (Indian tobacco)
}

\author{
ANDREW M. SIMONS* \& MARK O. JOHNSTON \\ Department of Biology, Dalhousie University, Halifax, Nova Scotia, B3H 4J1, Canada
}

\begin{abstract}
The timing of reproduction is an important life-history variable, especially for organisms that die following a single reproductive episode, such as the monocarp Lobelia inflata. The propensity to initiate flowering (to bolt) under a given set of conditions is expected to be shaped by natural selection acting on the norms of reaction for bolting behaviour over, for example, changing photoperiods. We study the genetic basis of bolting and of the plasticity of bolting using three continuously changing photoperiod regimes over two generations in a growth chamber experiment. Multiple genotypes from three populations are tested under three different photoperiod treatments mimicking early, mid, and late 'summer' during both generations. The frequency of bolting ranges from $88 \%$ under long days to $1 \%$ under short days. The overall heritability $\left(h^{2}\right)$ of bolting is found to be high, and increases later in the flowering season. Genetic variance for bolting is explained by genetic variance for threshold size itself, rather than for capacity to attain a fixed threshold size: genotypes that bolt most readily tend to be those that bolt at a smaller rosette size. No significant heritability of the plasticity of bolting behaviour is detected. Similarly to within populations, variation at the among-population level exists for bolting behaviour. There is no evidence for genetic population differentiation with respect to plasticity for bolting: although plasticity differs among populations within a generation, this population effect is not consistent between the two generations of the experiment.
\end{abstract}

Keywords: bolting behaviour, flowering time, heritability, life-history evolution, phenotypic plasticity, threshold traits.

\section{Introduction}

An organism's schedule of reproduction is a fundamental life-history trait; fitness is maximized only if this schedule is optimal with respect to an organism's particular pattern of growth, mortality and fecundity (McLaren, 1966; Roff, 1992). A schedule of reproduction has two major components: the timing of reproduction, and the proportional allocation of energy to reproduction, or reproductive effort. Organisms that die following a single bout of reproduction (semelparous), such as monocarpic plants, are ideally suited for the study of the life-history consequences of the timing of reproduction, for two reasons. First, with only one chance to reproduce, the cost of making an inappropriate flowering 'decision' is high, and it must be made in

*Correspondence and present address: Department of Biology, College of Natural Sciences, Carleton University, 1125 Colonel By Drive, Ottawa, Ontario, K1S 5B6, Canada

E-mail: andrew_simons@carleton.ca the face of unpredictable herbivore pressure (Simons \& Johnston, 1999) and season length. Second, the issue of reproductive effort is not confounded by trade-offs involving allocation among different reproductive episodes as it would be for iteroparous organisms.

Recent empirical work has advanced our understanding of the timing of reproduction in monocarps, but considerable gaps remain. For rosette-forming monocarpic plants, the reproductive mode is initiated at the time of stem elongation, or 'bolting.' For some monocarps, reproductive status is determined late during a season but bolting occurs only following 'vernalization' through an exposure to a cold period (de Jong et al., 1998). The timing of the onset of reproduction in plants that require vernalization is influenced by both plant size (Werner, 1975; Klinkhamer et al., 1987; Couvet et al., 1990; Klinkhamer et al., 1991) and, more rarely, age (Lacey, 1986a; Klinkhamer et al., 1987), as well as by interactions between plant size and conditions during vernalization (Klinkhamer et al., 1991; Karlsson et al., 1993). 
A large proportion of variation in the probability of bolting remains unexplained, however, and it is becoming evident that the basis of the flowering 'decision' is more complex than size or age alone. The threshold size for reproduction, although it may be characterized for a given year, is highly plastic: even in cases where a strong relationship exists between rosette size and the probability of bolting, significant among-year variation in size requirements has been found (Wesselingh, 1995). Investigating the norms of reaction characterizing this plasticity would therefore aid in understanding the control of reproductive timing in monocarpic plants.

Bolting can occur only if certain environmental and/ or physiological conditions are met. Some conditions may operate close to the time of bolting. Other conditions may operate much earlier - for example during a vernalization period. The conditions for bolting may be studied more easily for plants not requiring vernalization, because all or most of the requirements for bolting can be observed closer to the time at which bolting occurs. Very little is known about the behaviour and genetics of bolting in monocarpic plants that do not require vernalization. It has been found, however, that the size requirements for bolting in Lobelia inflata (Campanulaceae) are not fixed; they vary depending on time of year, with a larger size requirement later in the growing season (Simons, 1999). Few studies have assessed the genetic basis of bolting, but the year of bolting in offspring has been shown to resemble that of its parents (Lacey, 1986b), differences in the effect of vernalization on flowering behaviour exist within populations (Nordborg \& Bergelson, 1999) and, when measured, the heritability of threshold size for bolting in plants requiring vernalization has been found to be substantial (Wesselingh \& de Jong, 1995). Wesselingh \& de Jong (1995) selected for large and small threshold rosette size at bolting in Cynoglossum officinale (Boraginaceae), and found $h^{2}=0.35$ and $h^{2}=0.32$ for the two lines. They proposed that the relatively high heritability for a life-history character (Mousseau \& Roff, 1987) results from a 'flat fitness profile' near the optimal rosette size (Wesselingh \& de Jong, 1995).

In this paper we investigate the genetics and plasticity of bolting behaviour using a monocarpic perennial, Lobelia inflata, that does not require vernalization for bolting. Seeds exhibit nondeep physiological dormancy, have a strict light requirement for germination, and may germinate throughout the growing season (Simons \& Johnston, 2000). The quantitative genetics of bolting behaviour and its plasticity were studied using three continuously diminishing photoperiod treatments representing early, middle, and late summer (referred to as phototreatments $\mathrm{A}, \mathrm{B}$, and $\mathrm{C}$ ), over two generations in the growth chamber. The present experiment differs from earlier studies in that the bolting 'decision' itself, rather than the threshold size for bolting, is of interest, and it is measured as a dichotomous character within a single season of growth. Several additional life-history characters, including rosette size at the time of bolting, were measured so that genetic correlations between bolting behaviour and these characters could be assessed.

The same genotypes were used in each of the treatments so that the degree of plasticity of bolting expressed by a genotype over the different treatments could be measured, and the heritability of this plasticity could be obtained by offspring-on-parent regression. Although numerous studies have investigated the quantitative-genetic basis of plasticity, rarely has the quantitative genetics of the plasticity of a threshold character been assessed (Roff, 1994; Roff and Bradford, 2000).

Lobelia inflata has several favourable characteristics for such a study. First, this species is completely selffertilizing: the stigma is not exserted, but opens inside the closed anther tube, thus preventing outcrossing. Because heterozygosity decreases rapidly over generations of self-fertilization, seed parents and their offspring may be assumed to be genetically identical in $L$. inflata. In L. siphilitica, a predominantly outcrossing species, inbred progeny bolt less readily under field conditions than do progeny resulting from outcrossing (Johnston, 1992). Although other factors probably influence the relationship between rate of self-fertilization and inbreeding depression (Johnston \& Schoen, 1996), inbreeding depression is expected to be low in populations exhibiting self-fertilization, because selection can act against recessive deleterious alleles (Lande \& Schemske, 1985); it is therefore unlikely that variation observed in bolting behaviour in the present study could be attributable to variation in inbreeding depression. Furthermore, this species reproduces only once in its lifetime, and no alternative reproductive modes to seed production exist. Factors influencing reproduction within single seasons may thus be examined in detail for L. inflata.

\section{Materials and methods}

Seeds of $L$. inflata were collected from three populations: Martock, Nova Scotia; Mt. St-Hilaire, Quebec; and Harvard Forest, Petersham, Massachusetts. Seeds were stored in dark, dry conditions until use. Approximately 15 seeds from each of 12 genotypes from all three populations were placed, by genotype, on moistened filter paper in $6 \mathrm{~cm}$ Petri plates. The seeds were exposed to cool white light for 5 hours before being placed at $5^{\circ} \mathrm{C}$ for a 31-day dark stratification treatment. Three phototreatments were then established, each of which was 


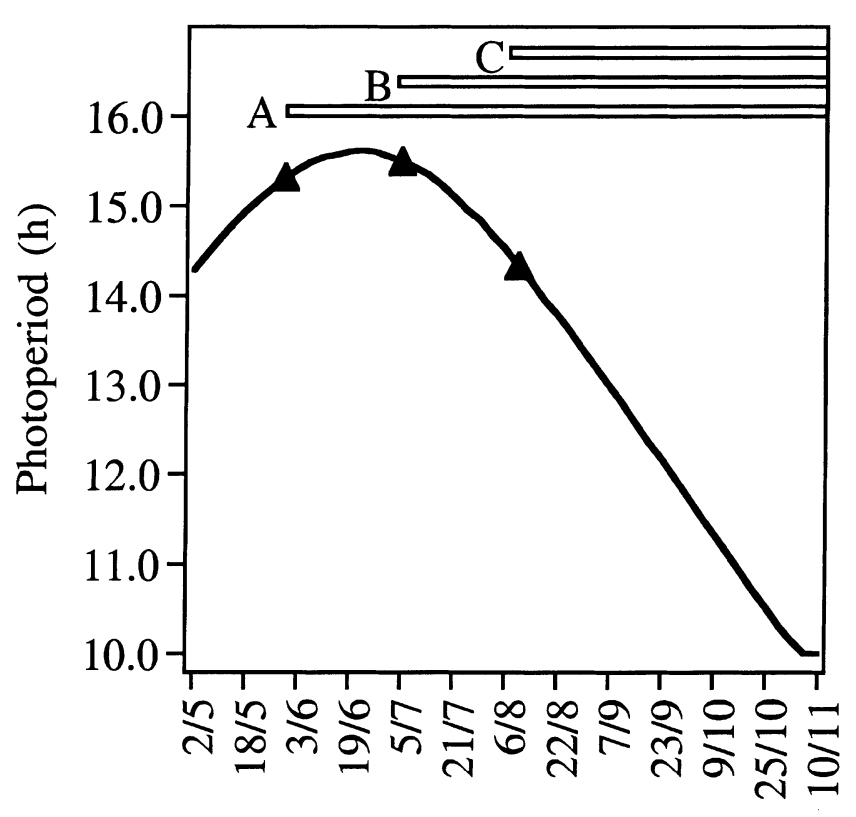

Simulated date (day/month)

Fig. 1 Growth chamber photoperiod schedule. Phototreatments $\mathrm{A}, \mathrm{B}$, and $\mathrm{C}$ were initiated at 35-d intervals (triangles). Bars at top indicate phototreatment duration.

designed to mimic the changing photoperiod of a different part of the growing season from early to late summer at a latitude of approximately 45 degrees North (Fig. 1). On day one for phototreatment A (early summer) the growth chamber was initially set at $21^{\circ} \mathrm{C} /$ $12^{\circ} \mathrm{C}$ and a $15 \mathrm{~h} 22 \mathrm{~min}$ light photoperiod. The range of experimental photoperiods includes those under which germination is likely to occur in the field. The thermoperiod was not adjusted along with the photoperiod; it remained at $15 \mathrm{~h} 22 \mathrm{~min}$ so that temperature effects would not confound those of photoperiod. One of three banks of lights was set for this photoperiod, the other two were set for $15 \mathrm{~min}$ later in the morning, and $15 \mathrm{~min}$ earlier in the evening to produce dusk and dawn. So that seed germination within each phototreatment would be synchronized, only seeds germinating over the peak germination period of seven days were used. Upon germination, five seedlings from each population and each genotype were transplanted individually to Kord cellpacks filled with ProMix.

Seeds for phototreatments B and C were subject to the same procedures that were followed for phototreatment A, but germination in the growth chamber (and thus photoperiod) was timed to be offset by $35 \mathrm{~d}$ and $70 \mathrm{~d}$, respectively (Fig. 1). Photoperiod was no longer adjusted when it had diminished to $10 \mathrm{~h}$ light (simulating the photoperiod of November 6). The 540 individuals were positioned in the growth chamber using a randomized block design: phototreatment, population, and genotype were randomized within four blocks of 135 plants.

Rosette size was measured as the length of the longest leaf, which is strongly correlated with rosette dry weight in this species $\left(r^{2}=0.94\right.$; Simons \& Johnston, 2000). Growth trajectories of each rosette were recorded until bolting, or until day 86 if the rosette did not bolt, and bolting date was recorded. Final size of nonbolters was recorded on day 126 of the experiment. Seeds of generation one were then harvested and all fruits of each individual were stored separately in glassine envelopes.

Seeds for generation two were derived from bolting individuals from phototreatment $\mathrm{A}$ of generation one. Insufficient seed was available for two genotypes from Harvard Forest from phototreatment A, and seed from phototreatment B was used in these two cases. In no case was seed from individuals of the short-day phototreatment (C) used. To found generation two, each genotype was represented by 20 seeds, five from each parent whenever possible. Furthermore, for this generation, only seeds from the first two fruits on the main inflorescence were used. Seeds were moistened and exposed to 5 hours of light before being placed at $6^{\circ} \mathrm{C}$ for 31 days. The same temperature regime and photoperiod schedule (Fig. 1) was used in this generation as for generation one, but new randomized positions within the growth chamber were used. Rosette measurements (longest leaf) were taken once per week on all individuals, and were continued until no growth in three successive weekly measurements was observed. Fruits were harvested upon ripening.

\section{Quantitative-genetic basis of bolting behaviour}

We treat bolting behaviour as a threshold trait and assume that the underlying liability of bolting results from a number of interacting physiological variables (Roff, 1997; p. 52). Whereas bolting vs. not bolting can be measured on individuals, the liability (defined below) of bolting for a genotype can be measured only by using multiple individuals. Here we investigate the quantitative-genetic basis of bolting by estimating the following with respect to bolting liability: heritability; population differentiation; plasticity associated with the three photoperiod treatments; heritability of this plasticity; and several genetic correlations.

For each genotype, phototreatment-wide liability was calculated as the deviation of the genotype's mean liability from the mean liability observed within a phototreatment. The distribution of liability within a phototreatment was assumed to be normal, with a mean of zero. The threshold for bolting within 
a phototreatment, $x_{\mathrm{p}}$, was obtained by converting the proportion bolting to the corresponding standard normal deviate, in units of standard deviations, using the PROBIT statement (SAS, 1989). Similarly, the deviation of the threshold from the genotype's mean, $x_{\mathrm{g}}$, was then calculated for each genotype. Each genotype's mean liability was then obtained by subtracting $x_{\mathrm{g}}$ from $x_{\mathrm{p}}$. This procedure was repeated for each phototreatment, and for both generations. Generation-wide liability was calculated in the same manner, except that a genotype's value for a given phototreatment was calculated as the deviation of the genotype's mean from the mean liability observed within the generation.

The conversion of bolting on the scale of proportions within a genotype to underlying liability is not possible when the genotype contains either $100 \%$ or $0 \%$ bolting, because the corresponding normal deviate is infinite. One solution to this problem is to simply drop those genotypes from the analyses. Rather than dropping genotypes with no variance, a 'pseudoliability' was calculated for these genotypes. The rationale behind this method is that an observed bolting frequency of 0 or 1 is based on a small sample of the true bolting frequency of the genotype which lies somewhere between 0 and 1 . If a genotype contained zero bolters, one bolter was added to the genotype along with a number of nonbolters in a proportion consistent with the overall proportions observed in the phototreatment (or generation, in the case of generation-wide liability). Likewise, if a genotype contained only bolters, one nonbolter and an appropriate number of bolters were added. Liability values were then calculated as above from the proportions for each genotype. This method, although it is conservative in that it has the disadvantage of diminishing genotypic effects (and thus underestimating heritability), allows for the inclusion of genotypes with extreme values.

The data consist of both 'affected' (bolted) and 'unaffected' (nonbolted) parents and their offspring, and the offspring-on-parent regression were not performed in the usual manner (e.g. Lynch \& Walsh, 1998), which uses only the affected parents and their progeny. Instead, liability values were calculated for each parental and offspring genotype. Thus, one liability value per genotype, based on several individuals, was obtained for each generation and for each phototreatment. Because this experiment included three phototreatments within both generations, liability could be calculated either for the separate phototreatments or for the entire generation across all phototreatments. Liability was calculated using both methods, and is referred to as phototreatment-wide liability and generation-wide liability, respectively.

Because data on individuals of the same genotypes within generations and over two generations were available, the heritability of liability of bolting could be calculated in two main ways: offspring-on-parent regressions, and analyses of variance. $L$. inflata is completely self-fertilizing, and offspring are assumed to be genetically identical to parents. Therefore, the slope (not twice the slope) of the regression coefficient estimates the heritability. All regressions were corrected for the effect of population by including population as a covariate after testing for homogeneity of slopes.

A genotype's plasticity across different phototreatments was calculated as the difference between its generation-wide liability values between pairs of phototreatments. Because bolting was assessed with respect to three phototreatments, three plasticity measures were constructed: the plasticity of liability over phototreatments A to B (plastAB), that over B to C (plastBC), and that over A to $C$ (plastAC). Similarly to the calculation of the heritability of bolting, the heritability of the plasticity of bolting was calculated using both offspringon-parent regression and ANOvA. Analyses were performed using SAS (1989): offspring-on-parent regressions were performed using PROCs GLM and REG; analyses of variance were performed using PROC GLM, and the variance components used in the calculation of heritabilities were estimated using PROC VARCOMP. All $F$-tests were constructed based on Zar (1984; pp. 470-476).

\section{Results}

\section{General results}

The overall frequency of bolting over the two generations of the experiment was 0.31 . The proportion bolting showed plasticity in response to day length, and decreased consistently with diminishing photoperiod, ranging from $88 \%$ under long days in the first generation to $1 \%$ under short days in the second generation (Fig. 2a). Two-way factorial ANOVAs in which all genotypes of the three populations were lumped, show that the mean rosette size at bolting did not differ among phototreatments $(F=1.24 ; P=0.291)$, but plants bolted at a significantly smaller size in the second generation $(F=31.95$; $P<0.0001$; Fig. 2 b). The time from germination to bolting did not differ significantly among generations $(F=3.02 ; P=0.083)$, but differed among phototreatments $(F=4.31 ; P=0.014)$ consistently over the two generations (interaction $F=0.00 ; P=1.00$; Fig. 2c).

The final rosette sizes of plants that did not bolt differed between generations $(F=86.25 ; P<0.0001)$ and decreased with diminishing photoperiods $(F=22.43 ; \quad P<0.0001)$ with the exception of large rosettes of the late-season phototreatment of generation two $(F=61.72 ; P<0.0001$; Fig. 2 d). 

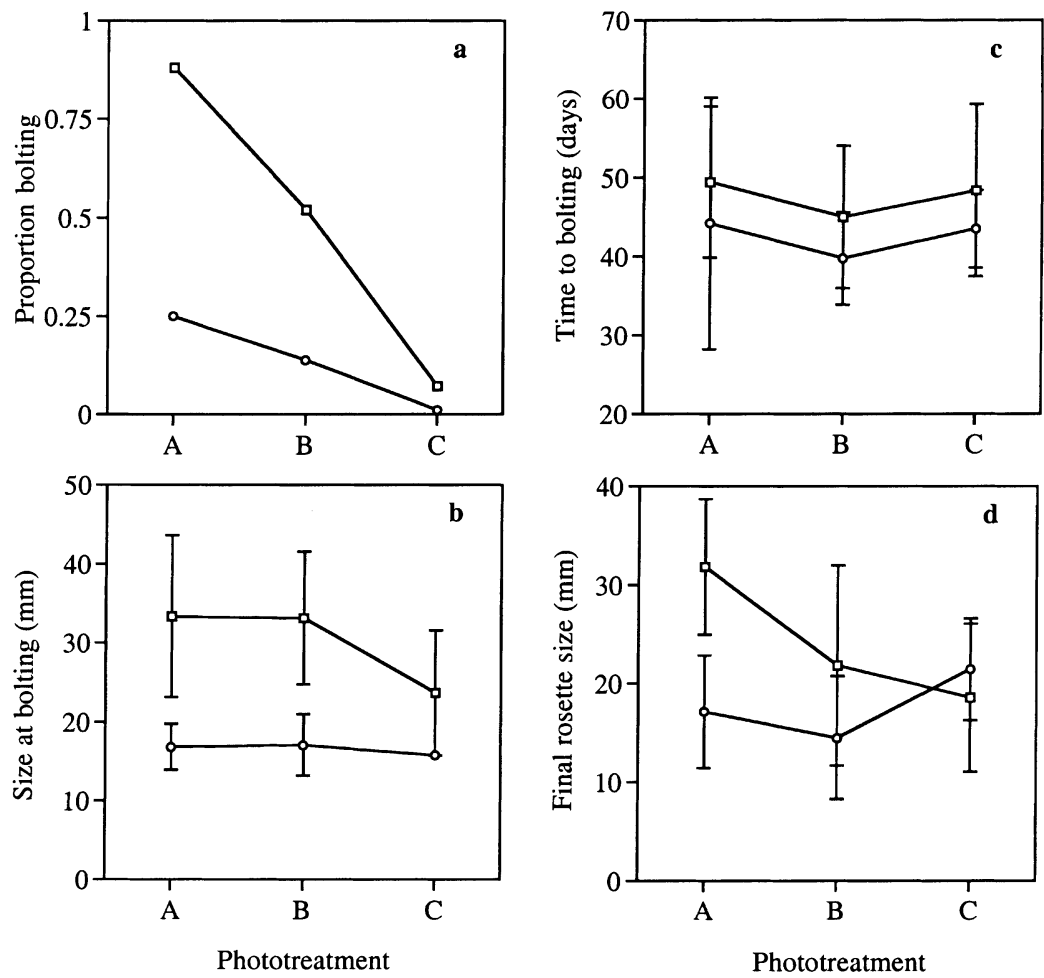

Fig. 2 Plasticity of various traits of Lobelia inflata over the three phototreatments. Squares indicate measurements taken for generation 1 , and circles indicate those taken for generation 2. Error bars indicate $\pm \mathrm{SD}$.

\section{Heritability of bolting}

The overall heritability of bolting on the underlying scale of liability was first calculated by offspring-onparent regression based on the mean of the three phototreatment-wide liability values (thus correcting for differences among phototreatments in mean liabilities) for each genotype within both generations. The homogeneity of slopes model indicates no significant interaction effect of population $(P=0.127)$, and the heritability of liability of bolting is highly significant (Table 1), with population entered as a covariate to correct for liability differences among populations. Genetic population differentiation $(\operatorname{pop} \beta)$, as estimated by the regression coefficient of the covariate, is also

Table 1 Heritability of bolting $\left(h^{2}\right)$, and population differentiation with respect to bolting (Pop $\beta$ ) in Lobelia inflata, both on the underlying scale of liability, based on offspring-on-parent regressions. Probability values are given in parentheses

\begin{tabular}{lll}
\hline & \multicolumn{1}{c}{$h^{2}$} & \multicolumn{1}{c}{ Pop $\beta$} \\
\hline Overall & $0.42(0.008)$ & $0.25(0.003)$ \\
Phototreatment A & $0.15(0.35)$ & $0.55(<0.001)$ \\
Phototreatment B & $0.23(0.17)$ & $0.20(0.11)$ \\
Phototreatment C & $0.37(0.001)$ & $0.00(0.96)$ \\
\hline
\end{tabular}

highly significant (Table 1). If the effect of phototreatment is ignored by using the generation-wide liability value for each genotype, the overall heritability is lower, but remains significant $\left(h^{2}=0.30 ; P=0.02\right)$.

Heritabilities estimated separately for each of the three phototreatments show an increase as the season progresses (Table 1). In no case does the regression slope differ significantly among populations. In contrast to heritability, there is a decreasing trend in genetic population differentiation as the season progresses (Table 1).

Results of ANOVAs confirm the trends in heritability observed for the offspring-on-parent regressions. Separate ANOVAs for each phototreatment, using population as a random main effect and genotype within population as a random nested effect, indicate that the heritability increases from $0.00(P=0.665)$ when measured in the early phototreatment to $0.208(P=0.108)$ in the intermediate, to $0.321(P=0.037)$ in the late-season phototreatment.

Because liability cannot be obtained for individuals, the genetic correlations between liability and other traits were calculated using the correlation of family means. The family mean correlation between bolting liability and rosette size at bolting is negative within both generations, although not quite statistically significant in the second (Table 2). There is no significant genetic correlation between liability and the time taken to bolt, 
Table 2 Family mean correlations between bolting behaviour in Lobelia inflata, expressed on the underlying scale of liability, and other life-history traits. Probability values are given in parentheses

\begin{tabular}{lccc}
\hline & Rosette size at bolt & Time to bolt & $\begin{array}{c}\text { Final rosette size } \\
\text { of nonbolters }\end{array}$ \\
\hline Liability_generation 1 & $-0.420(<0.001)$ & $-0.174(0.147)$ & $-0.532(<0.001)$ \\
Liability_generation 2 & $-0.333(0.058)$ & $-0.265(0.136)$ & $-0.119(0.220)$ \\
\hline
\end{tabular}

but there is some indication that the relationship is negative (Table 2). Nonbolting rosettes from genotypes with high liability values tended to be small (Table 2).

Within both generations, three liability values (one from each phototreatment) are available for each genotype. These liabilities can be used to estimate $h^{2}$ within generations based on resemblance among siblings. The heritability of bolting, based on the three phototreatment-wide liabilities, is $0.182(P=0.043)$ in the first generation, and $0.152(P=0.066)$ in the second generation. The effect of population explains no variance in the first generation (pop $\beta=0.00, P=0.421$ ), but explains a significant amount of variation in liability in the second generation (pop $\beta=0.204$, $P=0.001$ ). These heritabilities, because they are based on genotypic values measured in three environments, are reduced by the effects of genotype-by-environment interactions. Using generation-wide liabilities in the same analysis results in a heritability of 0.00 in both the first $(P=1.00)$ and second $(P=1.00)$ generations. Through the use of generation-wide liabilities, the different phototreatments are completely ignored; thus, this heritability is further reduced by the environmental component of variance across the three phototreatments.

\section{Population differences}

Whereas the availability of a single value of liability for each genotype precludes the estimation of heritabilities within phototreatments, it does not preclude analyses for population-level differences in liability. A fully factorial mixed-model ANOVA, including generation as fixed, and phototreatment and population as random main effects, was used. This ANOvA reveals (Table 3), besides a strong effect of phototreatment, a significant overall effect of population. Furthermore, this effect of population does not depend on phototreatment or generation.

Population effects were also analysed for rosette size at bolting and time taken to bolt. If analyses are performed for generations separately, a significant effect of population on rosette size at bolting is observed in the first generation, but not in the second. No consistent population differences were observed, however, for either rosette size at bolting or time taken to bolt (Table 3).

\section{Heritability of plasticity of bolting}

Bolting behaviour showed considerable plasticity over the three phototreatments in both generations (Fig. 2a), and an appraisal of the relative contribution of genetic variance to the total phenotypic variance in plasticity would be informative. The overall withinpopulation heritability of plasticity of bolting on the underlying scale of liability was calculated for the entire dataset using the plasticity of liability over phototreatments $\mathrm{A}$ to $\mathrm{C}$ for each genotype in an offspring-on-parent regression. No significant interaction effect of population is indicated by the homogeneity of slopes model $(P=0.704)$. The heritability of plasticity of bolting is low and nonsignificant (Table 4) when population is included as a covariate. There is evidence that the effect of population differs between generations, or of population-by-generation interaction because the regression coefficient of the covariate is strong and negative (pop $\beta=-0.461, P=0.003$ ), and this is further explored using ANOvA (see below). Offspring-on-parent regressions performed on the two separate plasticity measures reveal no significant heritability for either plastAB or plastBC (Table 4), and post hoc tests on populations separately show no heritabilities significantly different from zero (Table 4). Although nonsignificant, the population effects are negative for both of the separate plasticity measures (plastAB: pop $\beta=-0.313, P=0.077$; plastBC: pop $\beta=$ $-0.172, P=0.212$ ).

A nested random effects ANOVA tested the effect of population and genotype within population on plasticity for each of the plasticity measures. In this analysis, generations are used as the replicate observations within genotypes. The ANOvAs confirm the general results of the offspring-on-parent regressions: no significant within-population heritability of plasticity is found. Although two plasticity measures per genotype are available for each generation (plast $\mathrm{AB}$ and plastBC), these measures are not independent. 
Table 3 Sources of variation with respect to three reproductive characters in Lobelia inflata

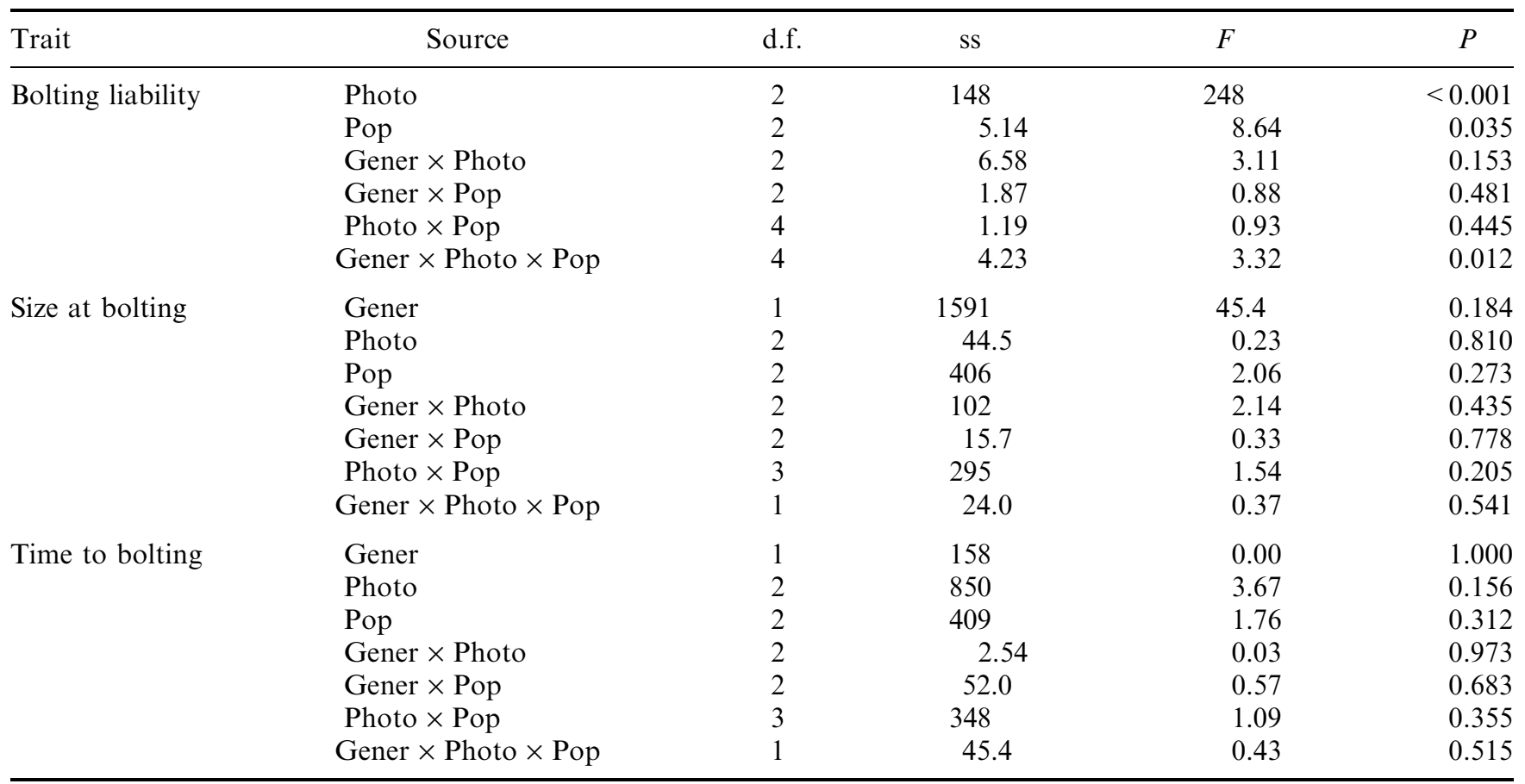

Characters were measured over two generations (Gener), under three phototreatment regimes (Photo), and for three populations (Pop). Factorial mixed-model ANOvAs were performed that included generation as fixed, and phototreatment, population, and all interactions as random effects. Because bolting liability is standardized to zero for both generations, the effect of generation for this variable is not included in the table. F-tests were constructed according to Zar (1984).

\begin{tabular}{lccc}
\hline & $\begin{array}{c}\text { Overall: Photo- } \\
\text { treatments A to C }\end{array}$ & $\begin{array}{c}\text { Phototreat- } \\
\text { ments A to B }\end{array}$ & $\begin{array}{c}\text { Phototreat- } \\
\text { ments B to C }\end{array}$ \\
\hline Phototreatment-wide & $0.049(0.74)$ & $0.014(0.94)$ & $0.164(0.33)$ \\
Martock & 0.000 & -0.146 & 0.001 \\
Mt. St. Hilaire & 0.062 & -0.071 & -0.057 \\
Harvard Forest & 0.085 & 0.053 & 0.295 \\
\hline
\end{tabular}

Table 4 Heritability of plasticity of bolting in Lobelia inflata, based on offspring-on-parent regressions. Probability values are given in parentheses
Plasticity over phototreatments A to B is inversely related to the plasticity over phototreatments $\mathrm{B}$ to $\mathrm{C}$ in both the first $(N=32, r=-0.426, P=0.015)$ and second $(N=36, \quad r=-0.518, \quad P=0.001)$ generations. Therefore, the question of whether there are amonggenotype differences in plasticity within generations could not be directly addressed using ANOVA.

Analyses of variance were performed, however, to test for differences in plasticity among populations. Twofactor, mixed model ANOVAs including generation, population and their interaction were performed for plastAB, plastBC and plastAC. These ANOvAs reveal no effect of population overall, due to a strong populationby-generation interaction (Table 5). However, the effect of population on overall plasticity (plastAC) is highly significant if included as a nested effect within genera-
Table 5 Population and generation effects on the plasticity of bolting on the underlying scale of liability, in Lobelia inflata

\begin{tabular}{lrrc}
\hline & ms & d.f. & $P$ \\
\hline Generation & 10.44 & 1 & 0.232 \\
Population & 0.17 & 2 & 0.707 \\
Generation $\times$ population & 3.64 & 2 & 0.001 \\
Within population (error) & 0.49 & 62 & \\
\hline
\end{tabular}

The mixed-model ANOVA is for the overall plasticity (phototreatments $\mathrm{A}$ to $\mathrm{C}$ ), and includes generation as fixed, and population and the interaction effect as random.

tion $(P=0.006)$. Whereas Martock exhibited the highest relative overall plasticity in the first generation, it showed the lowest in the second.

(C) The Genetical Society of Great Britain, Heredity, 85, 356-365. 


\section{Discussion}

This experiment was designed to investigate the quantitative genetic basis of timing of reproduction in the monocarpic perennial, Lobelia inflata. Bolting behaviour is highly plastic over the three photoperiod treatments (phototreatments) and differed between the two generations of the experiment in terms of the proportion bolting, rosette size at bolting, the time taken to flower, and other traits.

Traits that are influenced by a large number of loci (polygenic) may be phenotypically dichotomous if the phenotypic response depends on an underlying 'liability' (Falconer, 1989) exceeding a threshold value. Examples of such 'threshold' traits include cricket wing dimorphisms (Roff \& Simons, 1997), and mating behaviour dimorphisms in thrips (Crespi, 1986). Here we treat bolting behaviour as such a threshold trait and assume that the underlying liability of bolting is a product of a number of unmeasured, or unmeasurable, interacting physiological variables (Roff, 1997). Threshold size at bolting is not fixed in this species (Simons, 1999), and size is simply included as one of the many unknown variables interacting to produce a liability value. We analyse the variance in liability underlying bolting behaviour using the proportions of bolting observed among different genotypes. Genetic differences in bolting, then, should be interpreted as comprising all factors contributing to the determination of the bolting phenotype including, for example, any genetic differences in the interactive effects of rosette size and photoperiod.

With an overall heritability of 0.42 within populations, the response to selection on bolting might be expected to be rapid. This heritability is high in comparison to lifehistory traits in general (Mousseau \& Roff, 1987), and this is especially surprising considering that this species is self-fertilizing (Carr \& Fenster, 1994). Size at bolting is highly variable for this species (Simons, 1999). It is possible to ask whether genotypes that tend to bolt readily are those that attain a large size, or those that bolt at a smaller size. Interestingly, genetic correlations (as estimated by the family mean correlations) indicate that genotypes that bolt more readily tend to be those for which the threshold requirements for bolting were satisfied at a smaller rosette size. This implies that selection acting to increase bolting frequency would concurrently select for smaller rosette size at bolting.

Plants from three geographically separated populations were used, and significant differences in liability for bolting among the three populations exist. Although this result might be explained by genetic drift, the different environments may have selected for different 'rules' governing bolting behaviour.
The range of phenotypic expression of a character across different environments is known as phenotypic plasticity, and is commonly described by the character's 'norm of reaction.' A genotype capable of appropriate phenotypic expression in every possible environment would of course be at a selective advantage under changing environments. Given genetic variation for norms of reaction, adaptive norms of reaction should evolve just like any other trait, in response to selection. For example, genetic variation for phenotypic plasticity in the rate of stem elongation has been detected in L. siphilitica (Pigliucci \& Schlichting, 1995). Although much resident variation in plasticity of bolting behaviour is found in the present experiment, the variation is as high within as among genotypes. At the amongpopulation level, a strange phenomenon is observed: within generations, plasticity differs among populations, but a population exhibiting high average plasticity to phototreatment in the first generation exhibits low average plasticity in the second. It is possible that maternal environmental effects affect the expression of plasticity, and that these maternal effects changed over the two generations. This highly significant generationby-population interaction should be investigated further because, if this phenomenon proves consistent, single measures of plasticity could not be taken as characteristic of a population.

Although it was necessary to perform the present experiments under controlled conditions, there are several drawbacks to such an approach. For example, two iteroparous species closely related to $L$. inflata, L. cardinalis and L. siphilitica, bolt more readily during their first year of growth under greenhouse conditions than they do in the field (Johnston, 1992). Estimates of $h^{2}$ and genetic correlations depend both on population and environment (Falconer, 1989). Previous work, directly comparing heritabilities and genetic correlations measured in constant and variable environments (Simons \& Roff, 1994, 1996), found that heritabilities tend to be overestimated under constant conditions. The $h^{2}$ of 0.42 measured under growth chamber conditions, although providing strong evidence for the existence of genetic variation in the field, should thus be viewed as an overestimate of the true value. Furthermore, the heritabilities differ substantially for the three phototreatments, with the late-season phototreatment $(\mathrm{C})$ being characterized by both the lowest frequency of bolting and the highest heritability. Genetic variation for the timing of reproduction is expressed most strongly under comparatively severe environmental conditions in this experiment. It is important to note that a high heritability does not imply elevated genetic variance, only an elevated level of genetic variance relative to total phenotypic variance. Very few individuals bolted under 
short-day conditions; clearly, the total phenotypic variance of bolting for phototreatment $\mathrm{C}$ is low in comparison to that of the other phototreatments.

The advantages of a growth-chamber experiment are that it allows the manipulation of photoperiod conditions for an assessment of the genetic basis of bolting behaviour and its plasticity, and the genetic correlations between it and other traits. Although the present results indicate the potential for adaptive evolution of bolting behaviour, and reveal extensive plasticity in bolting behaviour across photoperiods, they do not address the issue of how norms of reaction for bolting might be associated with fitness. Manipulation experiments, designed to extend the range of phenotypes available for study, can aid in testing hypotheses on adaptive plasticity (Schmitt et al., 1999) under field conditions. We are presently analysing data from such an experiment, wherein fitness in the field is assessed for plants manipulated to bolt throughout the summer.

\section{Acknowledgements}

The authors thank J.A. Hutchings, S. Kalisz, I.A. McLaren, D. Ruzzante, and two anonymous reviewers for comments, and P. Wilson for collecting seeds from Harvard Forest, Massachusetts. This work was supported by Natural Sciences and Engineering Research Council (NSERC) grants to M.O. Johnston.

\section{References}

CARR, D. E. AND FENSTER, C. B. 1994. Levels of genetic variation and covariation for Mimulus (Scrophulariaceae) floral traits. Heredity, 72, 606-618.

COUVET, D., MihaliaK, C. A. AND Lincoln, D. E. 1990. Genetic and environmental effects on life-history of a facultative biennial. Oikos, 57, 161-166.

CRESPI, B. J. 1986. Territoriality and fighting in colonial thrips, Hoplothrips pedicularius, and sexual dimorphism in Thysanoptera. Ecol. Entomol., 11, 119-130.

FALCONER, D. S. 1989. Introduction to Quantitative Genetics, 3rd edn. John Wiley and Sons, New York.

JOHNSTON, M. O. 1992. Effects of cross and self-fertilization on progeny fitness in Lobelia cardinalis and L. siphilitica. Evolution, 46, 688-702.

JOHNSTON, M. O. AND SCHOEN, D. J. 1996. Correlated evolution of self-fertilization and inbreeding depression: an experimental study of nine populations of Amsinckia (Boraginaceae). Evolution, 50, 1478-1491.

DE JONG, T. J., GOOSEN-DE ROO, L. AND KLINKHAMER, P. G. L. 1998. Is the threshold size for flowering in Cynoglossum officinale fixed or dependent on environment? New Phytol., 138, 489-496.

KARLSSON, B. H., SILLS, G. R. AND NIENHUIS, J. 1993. Effects of photoperiod and vernalization on the number of leaves at flowering in 32 Arabidopsis thaliana cultivars. Am. J. Bot., 80, 646-648.

KLINKHAMER, P. G. L., DE JONG, T. J. AND MEELIS, E. 1987. Delay of flowering in the 'biennial' Cirsium vulgare: size effects and devernalization. Oikos, 49, 303-308.

KLINKhAMER, P. G. L., DE JONG, T. J. AND MEelis, E. 1991. The control of flowering in the monocarpic perennial Carlina vulgaris. Oikos, 61, 88-95.

LACEY, E. P. 1986a. Onset of reproduction in plants: size- versus age-dependency. Trends Ecol. Evol., 1, 72-75.

LACEY, E. P. 1986b. The genetic and environmental control of reproductive timing in a short-lived monocarpic species, Daucus carota (Umbelliferae). J. Ecol., 74, 73-86.

LANDE, R. AND SCHEMSKE, D. W. 1985. The evolution of selffertilization and inbreeding depression in plants. I. Genetic models. Evolution, 39, 24-40.

LYNCH, M. AND WALSh, B. 1998. Genetics and Analysis of Quantitative Traits. Sinauer, Sunderland, MA.

MCLAREN, I. A. 1966. Adaptive significance of large size and long life of the chaetognath Sagitta elegans in the Arctic. Ecology, 47, 852-855.

MOUSSEAU, T. A. AND ROFF, D. A. 1987. Natural selection and the heritability of fitness components. Heredity, 59, 181197.

NORDBORG, M. AND BERGELSON, J. 1999. The effect of seed and rosette cold treatment on germination and flowering time in some Arabidopsis thaliana (Brassicaceae) ecotypes. Am. J. Bot., 86, 470-475.

PIGLIUCCI, M. AND SCHLICHTING, C. D. 1995. Ontogenetic reaction norms in Lobelia siphilitica (Lobeliaceae): response to shading. Ecology, 76, 2134-2144.

ROFF, D. A. 1992. The Evolution of Life Histories; Theory and Analysis. Chapman \& Hall, New York.

ROFF, D. A. 1994. The evolution of dimorphic traits - predicting the genetic correlation between environments. Genetics, 136, 395-401.

ROFF, D. A. 1997. Evolutionary Quantitative Genetics. Chapman \& Hall, New York.

ROFF, D. A. AND BRADFORD, M. J. 2000. A quantitative genetic analysis of phenotypic plasticity of diapause induction in the cricket Allonemobius socius. Heredity, 84, 193-200.

ROFF, D. A. AND SIMONS, A. M. 1997. The quantitative genetics of wing dimorphism under laboratory and 'field' conditions in the cricket Gryllus pennsylvanicus. Heredity, 78, 235-240.

SAS. 1989. SAS/STAT user's guide, version 6, 4th edn. Cary, NC.

SCHMITT, J., DUDLEY, S. A. AND PIGLIUCCI, M. 1999. Manipulative approaches to testing adaptive plasticity: phytochromemediated shade-avoidance responses in plants. Am. Nat., 154, S43-S54.

Simons, A. M. 1999. Evolution in Response to Environmental Unpredictability in Indian Tobacco, Lobelia inflata (Campanulaceae). PhD Thesis, Dalhousie University.

SimONS, A. M. AND JOHNSTON, M. O. 1999. The cost of compensation. Am. Nat., 153, 683-687.

SIMONS, A. M. AND JOHNSTON, M. O. 2000. Variation in seed traits of Lobelia inflata (Campanulaceae): sources and fitness consequences. Am. J. Bot., 87, 124-132. 
SIMONS, A. M. AND ROFF, D. A. 1994. The effect of a variable environment on the genetic correlation structure in a field cricket. Evolution, 48, 1637-1649.

SIMONS, A. M. AND ROFF, D. A. 1996. The effect of environmental variability on the heritabilities of traits of a field cricket. Evolution, 50, 267-275.

WERNER, P. A. 1975. Predictions of fate from rosette size in teasel (Dipsacus fullonum L.). Oecologia, 20, 197-201.
WESSELINGH, R. A. 1995. Ecology and Genetics of Reproductive Timing in Facultative Biennial Plants. Dissertation, Leiden University.

WESSELINGH, R. A. AND DE JONG, T. J. 1995. Bidirectional selection on threshold size for flowering in Cynoglossum officinale (hound's-tongue). Heredity, 74, 415-424.

ZAR, J. H. 1984. Biostatistical Analysis. Prentice-Hall, Englewood Cliffs, NJ. 